\title{
Brasilia: utopía y construcción del mito
}

\author{
Ana Virgínia Queiroz*
}

\begin{abstract}
Resumo: O artigo trata de como Brasília, uma cidade concebida e construída dentro dos parâmetros de racionalidade, foi circundada por todb um processo não scmente utópico, como também por um processo mitológico, que foi utilizado politicamente como estratégia de marketing, com o dojetivo de gerar o entusiasmo necessário para que os trabalhadores e o povo acreditassem que estavam construindo uma cidade destinada a inaugurar uma nova civilização redentora.
\end{abstract}

Palavras-chave: mito; imaginário popular; utopia.

En 2007 se completarán 50 años del Plano Piloto de Brasilia. Planeada para ser la ciudad racional, en la que la funcionalidad estuviese presente en todo su trazado, curiosamente, la nueva capital, también fue circundada por una mitología, que interpretaba la urbe como un marco de una nueva era y la cuna de una civilización grandiosa.

Son muchos los creen que la capital de Brasil, fue antevista y profetizada 77 años antes de su creación. Según esta versión, en el año 1883, un padre italiano llamado João Bosco, en una reunión de su congregación, describe un sueño que fue interpretado como una revelación (Figura 1). En su sueño, aparecía un mensajero divino que le habla de una ciudad, que sería construida entre los paralelos 15 e 20 y en la cual, quedaría plasmada una nueva civilización. El sacerdote habría sido conducido por ángeles hacia la América Latina, en un viaje que recorrió la selva amazónica, Paraguay, y Argentina, llegando hasta el interior de Brasil. En este momento, el canónigo escuchó una voz afirmando que en medio de aquellas montañas,

\footnotetext{
* Pesquisadora da Universidade de Brasília, Gestora Cultural. Atua também como curadora de exposições em Centros Culturais. Atualmente ocupa a Coordenação de Eventos Culturais da BCE-UnB, 2006. Doutora em História da Arte pela Universidade Complutense de Madrid (2005).
}

surgiría la civilización de la tierra prometida, donde mana leche y miel.

La predicción es oficialmente reconocida y citada, incluso por algunos cronistas de la "historia" de Brasilia, como por ejemplo Helio Silva y Adirson Vasconcelos (Vasconcelos, 1978). D. Bosco fue transformado en patrón de Brasilia. En su homenaje, fue construida una Ermita triangular en la región de los lagos, uno de los lugares nobles de la ciudad, además de una gran iglesia.

Incluso en Brasilia, el sueño de D. Bosco es conmemorado oficialmente hasta los días de hoy. A su vez, en el ámbito político, fue construida toda una ideología para dar soporte a esa mitología, en el sentido de respaldar a Brasilia. Juscelino Kubitschek, el presidente electo a finales de 1955, se transformó en una figura llave en la concepción y amplificación de esa mitología.

Es sabido, que inicialmente Kubitschek no había previsto, en su programa de gobierno, el objetivo de cambiar la capital del país. En su libro Por que construí Brasília explica, que por ocasión de la campaña presidencial, eligió un alejado y pequeño pueblo del interior del país para hacer su primer encuentro, con el objetivo de presentarse como candidato a presidente. En este pequeño pueblo, hizo un discurso en que 
Figura 1 - Mapa que describe la visión de d. Bosco.

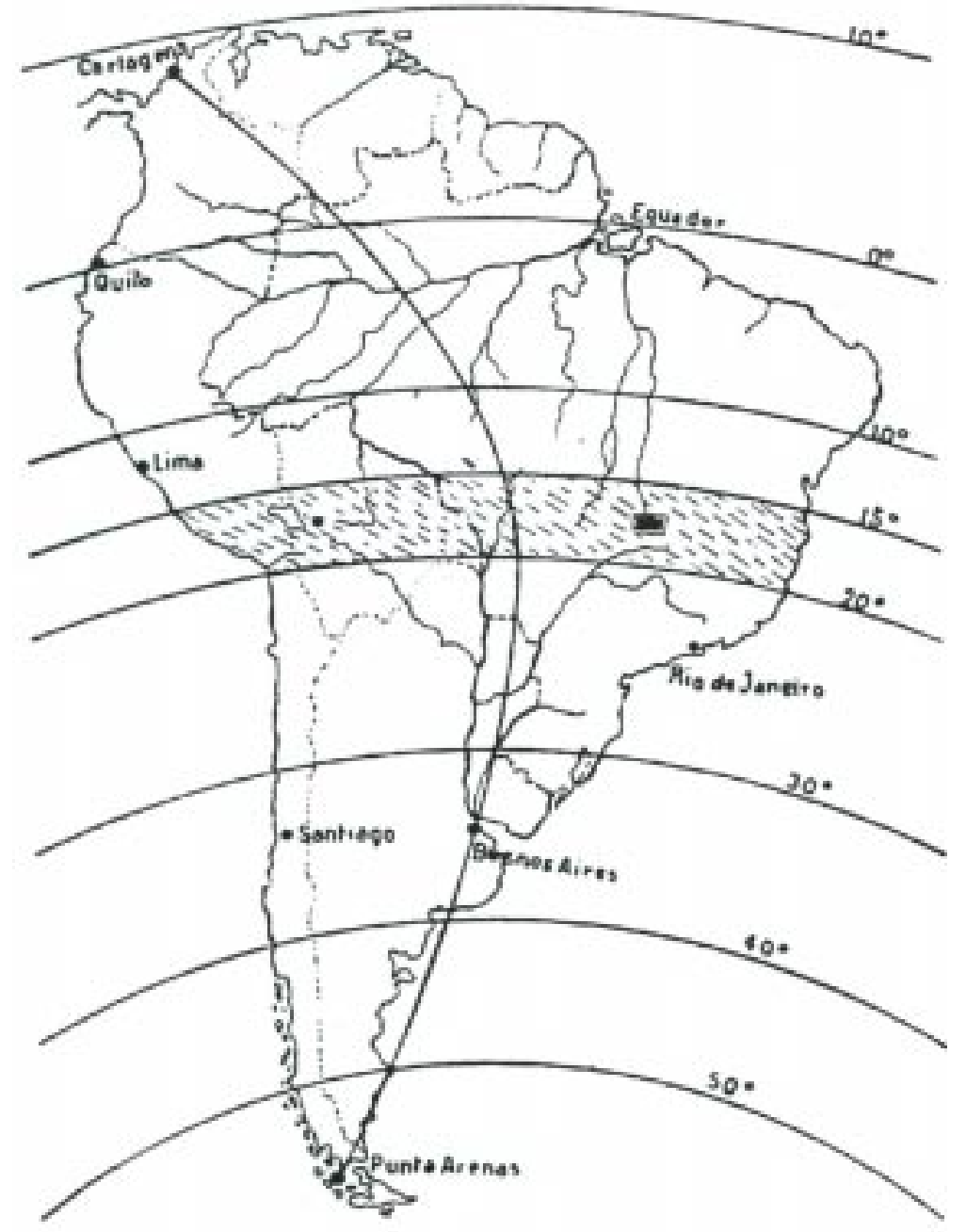

Fuente: Vasconcelos Adirson, A mudança da Capital, Brasília, Ed. Independência, 1978, p. 74.

prometía cumplir con rigor la constitución del país. Después de su intervención política, como hacia habitualmente, se quedó entre los electores para contestar las posibles preguntas. En ese momento, fue interpelado por uno de ellos, que le preguntó si realmente tenía la intención de cumplir la constitución y si pondría en práctica el dispositivo normativo, vigente en la Constitución, que previa la capital brasileña establecida en el centro del país. Recuerda Kubitsckek en su mencionado libro.

A pergunta era embaraçosa. Já possuía meu Programa de Metas e, em nenhuma parte dele, existia qualquer referência àquele problema. Respondi, contudo, como me cabia fazê-lo na ocasião: "Acabo de prometer que cumprirei a
Constituição e não vejo razão porque esse dispositivo seja ignorado. Se for eleito, construirei a nova capital e farei a mudança da sede do governo". (Kubitschek, 1975, p. 8)

Según JK, su respuesta fue política, sin embargo, es a partir de ese hecho, donde según él, empieza a reflexionar sobre la idea del cambio de la capital. En cuanto al recorrido en el interior del país, se daba cuenta de los vacíos demográficos en el territorio brasileño y constata:

O grande desafio da nossa história estava ali: seria forçar-se o deslocamento do eixo do desenvolvimento nacional. Ao invés do litoral que já havia alcançado certo nível de progresso, povoar-se o Planalto Central. O núcleo populacional, criado naquela longínqua região, 
espraiar-se-ia como uma mancha de óleo, fazendo com que todo o interior abrisse os olhos para o futuro grandioso do país. Assim, o brasileiro poderia tomar posse do seu imenso território. E a mudança da capital seria o veículo. O instrumento. (Kubitschek, 1975, p. 8-9)

Desde estas reflexiones, Kubitschek, va a integrar a su plano de metas, la construcción de la nueva capital, denominando a ese objetivo "Meta Síntesis".

Así, el futuro presidente, inicia una campaña con el propósito de articular la concretización de la idea de Brasilia. Para eso, empieza a elaborar una argumentación basada en una concepción del desarrollo nacional y de la modernización del país. Estaba seguro de que para edificar y concretizar la nueva capital, tendría que plasmar una propaganda que no solamente convenciera, sino que también fuera capaz de arrebatar entusiasmo al mayor número posible de ciudadanos brasileños. Realmente la idea de una capital en el centro del país era antigua, pero siempre fue mencionada con una dosis muy gran de escepticismo, y verdaderamente nunca contagió a los brasileños, en su gran mayoría acostumbrados a una urbanización a la orilla del mar. En ese contexto, Kubitschek, juega un papel fundamental en la construcción de la mitología de Brasilia. Confiesa en sus memorias, que incluso antes de que la ley de la transferencia fuese aprobada por el congreso, anticipó numerosas providencias para acelerar el proceso del cambio y afirma que entre esas providencias "[...] enningún momento fue olvidada la imprescindible movilización psicológica del pueblo" (Kubitschek, 1975, p. 44, grifo nuestro).

Para Kubitschek, "Esperanza y Desanimo" existían como agentes psicológicos individuales, y estos dos sentimientos tenían una correspondencia con la situación social del país. Confiesa haber leído a Eric From y según su interpretación de From, el presidente creía que "si el pueblo tuviera motivos para creer que estaba marchando para un futuro mejor podría mover montañas" (Kubitschek, 1978, p. 23, grifo nuestro).

Bojunga, en la biografía del presidente, confirma ese perfil.
JK foi pedagógico: queria mudar a mentalidade do brasileiro e a divulgação visava alterar o ânimo do país, fazê-lo tomar conhecimento de suas forças recônditas, quebrar tabus sobre sua incapacidade congênita para mudar o destino, abandonar o conformismo e o fatalismo em relação à pobreza. $\mathrm{O}$ Brasil, dizia, estava condenado a ser grande - era questão de tempo. (Bojunga, 2001, p. 427)

Es verdad que JK era un hombre con un gran carácter realizador. Ya había proporcionado pruebas de esto como alcalde de Belo Horizonte cuando, incluso, hizo construir el parque de Pampulha con su famosa Iglesia. Era un hombre audaz y asumió la construcción de la capital con una determinación impresionante. Su fuerza y carisma fueron imprescindibles para el convencimiento de sus auxiliares, muchos de ellos aprensivos de que una tarea de tal dimensión, no podría ser realizada en tan poco tiempo. Algunos temían que Brasilia se volviese el túmulo político del presidente, en cuanto la oposición confiaba que eso ocurriera. La determinación y obstinación del presidente fue más fuerte. $\mathrm{Su}$ equipo de colaboradores fue convencido y contagiado por el entusiasmo permanente de Kubitschek, y a partir de entonces, al unísono, todos trabajaron para dar forma a una argumentación consistente, que justificó Brasilia.

Foram três horas de vôo; confesso não ter tido boa impressão do lugar. Longe, longe de tudo, e a terra vazia e abandonada. Mas o entusiasmo de JK era tal, e o objetivo de levar o progresso para o interior tão válido, que acabamos, todos, com ele concordando. (Niemeyer, 2000, p. 35)

Al elegir Brasilia como meta síntesis, argumentaba Kubitschek, que la construcción de la nueva capital, integraría al vasto territorio brasileño, llevaría el progreso económico al interior del país y posibilitaría que Brasil asumiera sus riquezas. Por eso, Brasilia concurriría como alabanza para rescatar el país del subdesarrollo.

Para Kubitschek, Brasilia sería el símbolo de la modernidad brasileña. A través de la nueva capital, Brasil podría alcanzar el destino de ser moderno y de transformarse en una nación del primer mundo. Brasilia, concretizaría el ideario 
de una nación destinada a la modernidad. Con Brasilia, Brasil iniciaría un nuevo ciclo, en dirección a la prosperidad económica entre las naciones más modernas del planeta.

Esta manera de argumentar Brasilia, tuvo una correspondencia en el imaginario social de los trabajadores que vinieron a Brasilia con el sueño de construir una vida mejor. Juscelino Kubitschek y su equipo, promovieron la "imprescindible preparación psicológica del pueblo" (Kubitschek, 1975, p. 44) aliando los argumentos racionales del desarrollo y de la búsqueda de la modernidad, en un aura mítica con contenidos místico religiosos. Lo hicieron deliberadamente, aunque a la vez también fueron tomados por el mismo clima.

Vale recordar el sueño de D. Bosco anteriormente citado. El sueño del santo fue divulgado en la prensa en 1958 como una profecía, por iniciativa de Israel Pinheiro, el presidente de la poderosa Compañía Urbanizadora de Brasilia la Novacap. Según Vasconcelos, todavía en el inicio de la construcción de Brasilia, Pinheiro supo del sueño profético del santo italiano D. Bosco, que preveía que surgiría una nueva ciudad en el centro de América del Sur. Por encargo suyo, fueron hechas investigaciones en Italia que confirmaron que el sueño estaba registrado en el volumen XVI en las Memorie biografiche de Dom Bosco. Israel Pinheiro pronto providenció la divulgación del "SueñoVisión de D. Bosco" relacionando el mismo a la ciudad que empezaba a ser construida y mandó erguir una ermita en homenaje al santo (Vasconcelos, 1978, p. 72). A la vez, Kubitschek desarrollaba y reforzaba los argumentos míticos de Brasilia:

Meditei sobre a grande civilização que surgiria entre os paralelos 15 e 20 justo na área em que se estava construindo Brasília. O lago, da visão do santo, já figurava no plano piloto do urbanista Lúcio Costa. E a terra prometida, anunciada repetidamente, pela misteriosa voz, ainda não existia de fato, mas já se configurava através de uma aspiração coletiva, que passara a constituir uma aspiração nacional. Ali, 'emergeria leite e mel’. (Kubitschek, 1978, p. 19)

En la misma línea de intención de construcción del mito, Ernesto Silva, también integrante de la directoria de la Novacap y uno de los primeros que escribieron sobre la "historia" de Brasilia, y que durante el gobierno de JK fue el presidente de la comisión, diserta en la introducción de su libro Historia de Brasilia.

No dia 21 de abril de 753. a.C., Rômulo fundava, no Monte Palatino, uma cidade que seria o marco de uma nova era no Mundo Pagão - a Roma dos Césares -, o berço da de Civilização Cristã. Quis a Providência Divina que, no mesmo dia, 27 séculos mais tarde, uma plêiade de homens destemidos presenteasse Brasília ao Brasil, cumprindo assim os desígnios eternos manifestados na Visão Profética de D.Bosco: 'quando escavem as minas aqui escondidas no meio destas montanhas, surgirá, neste lugar, a grande civilização, a terra prometida, de uma riqueza inconcebível'. (Silva, 1963, p. 7)

No es raro encontrar la idea mitológica de Roma asociada a Brasilia, relacionando la ciudad con el mismo destino grandioso. Como si la nueva capital se volviese la caput mundi, inauguradora de una nueva civilización.

Como está claro, un conjunto de imágenes e ilusiones fueron sembradas y acabaron siendo internalizados por parte de la población. En su origen, el mito de Brasilia tuvo su nacimiento en formas político-ideológicas, originadas de un proceso intelectual, en parte deliberado y en parte inconsciente. Inconsciente, porque en cierto grado, al construir los planteamientos racionales o legendarios, los mismos se despliegan de las intenciones lógicas y reflejan la expresión de deseos y esperanzas, que también vienen relacionados a una actitud emocional de sus propios creadores.

Para Moreira, la idea de consenso y euforia, en torno a la nueva capital, en cuanto al símbolo que es, es sobre todo uno de los resultados de la 'fetichizacion' de Brasilia. En su estudio, la investigadora concluyó, que ese proceso fue implementado por los sectores que tenían interés en la urgencia del cambio de la capital. Pero también fue verdad que, conforme las obras progresaban, creció rápidamente el apoyo al proyecto "mudancista" (Moreira, 1998, p. 2867). Aún vale subrayar que según la historiadora 
[...] “as histórias de Brasília” não são, de fato, historiografia. São narrativas ideológicas [...]. A ideologia vestiu-se de história, e de forma sistemática buscou legitimar a construção da nova capital. A formulação da "história de Brasília”, portanto, é uma clara manipulação da idéia popular de história e de historiografia. (Moreira, 1998, p. 66)

Todo discurso apologético de Brasilia tuvo clara intención de tocar al pueblo a través de la emoción. Fueron creadas estrategias para fomentar el imaginario social, que no era otro sino lo más antiguo de los hombres: Encontrar la tierra prometida, vivir en una tierra próspera, sin conocer el hambre, sin sequía ni epidemias, donde pudieran tener una vida digna y feliz. Las resonancias del discurso de Brasilia estimulan ese imaginario, que tiene raíces en la mitología de El Dorado, de la Tierra Prometida y de la construcción del Nuevo Mundo. Para eso incluso, también relacionan la marcha a Brasilia con las "Entradas y Banderas", cuando los portugueses y luso brasileños se adentraron en el "sertão" y se rentaron los peligros de la selva en busca de oro, esmeraldas y diamantes.

La construcción del mito de Brasilia, viene así asociada a los mitos citados. Vale citar Jung, a través de Pelayo, en su estudio sobre mitos y símbolos políticos.

Jung ha explicado psicológicamente la reiteración de los motivos míticos viendo en ellos expresiones del inconsciente colectivo existente en la psique de cada persona individual y cuyo contenido no se debe a experiencias personales, sino a experiencias colectivas constantemente repetidas a lo largo de la historia desde el comienzo de la vida. Estas experiencias se configuran en lo que Jung denomina arquetipos, que son así 'ideas estampadas en el cerebro humano' que 'no pertenecen al dominio de la historia personal, sino a los secretos de la historia de la humanidad. (Pelayo, 1964, p. 65)

En efecto, la estrategia del discurso de Brasilia, alió toda una demostración lógica, al lado de una formulación con contenidos míticos religiosos y de tradición histórica. Ese discurso, se reveló bastante inteligente y eficaz, favoreciendo una integración en el campo social y político, lo que posibilitó el apoyo necesario para la construcción de la nueva capital. Así también, todo un ordenamiento de conceptos sobre la utopía de la modernidad, vinculada a la ideología del desarrollo, dio amplitud a los planteamientos de la edificación de Brasilia.

A ese respecto, vale recordar la distinción entre la utopía y el mito. Sabemos que los argumentos utópicos, están conectados a un procedimiento mental, construido a través de un sistema de conceptos, que indica posibles tácticas de elaboración plausibles. En contrapunto, el mito manifiesta una cualidad existencial y tiene una representación misteriosa.

Por otra parte, Pelayo, explica el modo en que ciertos movimientos de la primera posguerra mundial, como el fascismo y el nacional socialismo, fabricaron conscientemente mitos, a fin de utilizarlos como una manera de establecer un consenso social y favorecer una integración política. Según el investigador, una "creación racional y deliberadamente calculada para lograr un objetivo no es propiamente hablando, un mito, pero sí opera como tal respecto a la masa a la que va dirigido" (Pelayo, 1964, p. 35).

En efecto, en los argumentos que defendían Brasilia, pueden verse mezcladas, la perspectiva utópica y mítica aliada a las teorías del desarrollo y a los conceptos geopolíticos. Realmente, la argumentación racional sobre Brasilia poseía respaldo en una elite de privilegiados, si consideramos incluso, que el país tenía un alto porcentaje de analfabetismo. ¿Qué podrían saber los obreros de Brasilia sobre la teoría del desarrollo, la utopía de la arquitectura moderna o de los conceptos de la modernización del país? No es difícil concluir, a través de diversas declaraciones de la época, que sabían muy poco y de modo muy simplificado e incluso, que lo desconocían completamente, pero que creían en un conjunto de imágenes, adheridas a través del discurso mítico y que actuaban en el imaginario social. Imágenes, que venían aliadas a los argumentos en defensa de la nueva capital: ciudad de una nueva era, ciudad moderna, ciudad del futuro, ciudad del nuevo mundo, etc.

Esto motivó la creencia, de que la ciudad que ellos estaban construyendo, redimiría el país y engendraría una nueva sociedad con prosperidad para todos. Tal creencia, les dio fuerza 
y entusiasmo, necesarios para una especie de cruzada en el trabajo, la cual desconocía los límites del cansancio. A ese respecto escribe Silva.

Tornou-se imperativo, portanto, que cada soldado dessa primeira linha de batalha se armasse de bravura absoluta, se revestisse de falta de ambição e se empolgasse do renovado espírito de pioneirismo que deu corpo e alma ao perfil do bandeirante [...]. Por isso ao lidador da primeira hora de Brasília não foram permitidos o ócio, a pausa, a vacilação. Daí a dureza das obrigações QUASE DESUMANAS, que todos sentiram, nos regimes de serviço e na exigência da rapidez e da perfeição da obra. (Silva, 1963, p. 9)

Brasilia fue construida en apenas tres años y diez meses, a un ritmo impresionante. Durante ese período, la construcción no paraba y los obreros se alternaban días y noches, en dos turnos de dieciséis horas.

Fue el llamado "Espíritu de Brasilia" y el tiempo heroico de la construcción. Palabras comunes, durante estos años, fueron cargadas de un sentido casi mágico. "La capital de la esperanza", "Trabajadores heroicos", "La conquista ciclópea".

En cierta medida, esa creencia de que la ciudad moderna sería una ciudad de redención, ya estaba presente en los escritos de Le Corbusier. Son resonancias míticas presentes en el discurso utópico.

Una época nueva comienza y nuevos hechos sobrevienen. Y para comenzar, el hombre tiene necesidad de una morada y de una ciudad. La morada y la ciudad resultarán del nuevo espíritu, del sentimiento moderno, fuerza irreversible, desbordante, fuera de todo control, pero resultante del lento trabajo de nuestros padres. Es un sentimiento nacido de la más ardua labor, de las investigaciones más racionales: es un espíritu de construcción y de síntesis guiado por una concepción clara. (Corbusier, 1971, p. 30)

Brasilia sería la concreción de la ciudad moderna, la ciudad del futuro, capaz de crear una nueva sociedad, una nueva y luminosa cultura y un nuevo hombre. Una ciudad, que irradiaría un nuevo principio, y con ello, un nuevo orden. Existía la sensación, en estos tiempos, que quedarían cancelados todos los antiguos antagonismos; la oposición entre patrón y obrero sería superada en una nueva sociedad.

Sobre ese tema recuerda Oscar Niemeyer en una declaración al director de cine Wladimir de Carvalho. El arquitecto registra en el documental que en esta época todos ellos vivían con obreros en las mismas casa populares, comían en los mismos restaurantes y por eso había una ilusión de que estaban construyendo una ciudad distinta, una ciudad donde los hombres serían más hermanos y felices (Niemeyer, 1991).

Niemeyer revela, que aunque supiera que la arquitectura moderna de la ciudad, aisladamente no tendría capacidad de cambiar las condiciones del país, reconoce que en el período "heroico" de la edificación, había un clima que favoreció el sentimiento de que sería posible construir una ciudad justa e igualitaria.

La verdad es que en 1958, en plena epopeya de la construcción de Brasilia, Niemeyer tenía esa ilusión, que pasada la euforia, volvería a reconsiderar. No obstante, en esa época, su tono era de un idealismo utópico. Hablando sobre la ciudad contemporánea, decía que estaban viviendo una nueva etapa en la historia de los hombres. Según el arquitecto, las ciudades serían modernas y no se restringirían a una extraordinaria demostración de tecnología y belleza más, sí, serían modernas porque se tornarían "ciudades de hombres libres y felices" (Niemeyer, 1958, p. 6).

A la vez, JK se auto impone la imagen de un presidente que cancelaría una época y daría paso a otra. Para el presidente, Brasilia también era la frontera entre dos "Brasiles". Según él

Vivíamos, naquela época, um período de transição. Brasília foi o marco que assinalara a fronteira que separava dois Brasis. De um lado, ficara uma nação de 460 anos, litorânea, rotineira, pessimista, subdesenvolvida; e, do outro, nascida em 21 de abril, uma outra, audaz, corajosa, radiante, otimista e, sobretudo, atrevida. (Kubitschek, 1978, p. 373)

Vale observar, que en esta concepción, JK identifica Brasilia con características que eran 
resaltadas como cualidades de su propio temperamento. "Audaz", "corajosa", "radiante", "optimista", "atrevida". Nótese que son adjetivos en general inherentes a la personalidad humana. No son característicos de una ciudad.

Utilizando ese recurso, Kubitschek, no tan solo se coloca como el responsable para el proceso de concretización del cambio de la capital, sino que también intenta vincular su imagen a la de un nuevo Brasil idealizado.

Todo este clima de la época, de la construcción, fue llamado por JK y sus colaboradores "Espíritu de Brasilia".

A exortação que fazia aos trabalhadores não era só insistente, mas orientada no sentido de integrá-los desde logo no que denominei "Espírito de Brasília". Tratava-se de uma norma de comportamento humano: de uma nova filosofia - se o quiserem - a qual, sendo infiltrada nos espíritos, aumentaria o rendimento dos braços. Procurava despertar em cada trabalhador, por muito humilde que fosse sua tarefa, um sentimento de solidariedade em relação à cidade que estava construindo. (Kubitschek, 1978,p. 155)

"El Espíritu de Brasilia" (suerte de categoría mágica) es un recurso utilizado y reconocido por el propio Kubitschek, como estrategia psicoideológica, con el objetivo de multiplicar la capacidad de producción de los trabajadores, en los canteros de obras de la nueva ciudad. Es verdad, que el referido recurso se reveló eficaz, porque favoreció una integración y una euforia entre los trabajadores, lo que posibilitó la construcción de Brasilia en un tiempo record, pero bastante cuestionable, ya que se concretizaba en gran parte, como una resignación o total entrega de los trabajadores a un régimen de trabajo de extorsión.

De ahí, la importancia que adquiere la conducción de lo imaginario y la apelación a lo simbólico y mitológico, aliado a los argumentos geopolíticos y socioeconómicos, como instrumentos legitimadores de Brasilia. Sin esa mitología, que a través de significaciones imaginarias justificase la ciudad, quizás ella aparecería ante la conciencia de una parte de las personas, que ahí trabajaban, como un acto de coerción y sometimiento.
Como bien han resaltado Ledrut (1987, p. 55 ), a través de la función equilibradota de lo imaginario, o Maffesoli, por el táctica a la manipulación política del mito y del imaginario al servicio de la legitimación de una causa (Maffesoli, 1992, p. 29) se alcanza el acatamiento entusiasmado de la construcción de Brasilia, que en la labor de las obras en gran medida, se traduce en una servidumbre voluntaria.

\begin{abstract}
The present article is about the way Brasilia, a city conceived and built within parameters of rationality, was surrounded by a process of utopia and mythology, that was utilized both for political marketing purposes, generating the necessary enthusiasm so that workers and the people believed to be building a city destined to laundh a new redemptive civilization.
\end{abstract}

Key-words: myth; popular imagination; utopia.

\section{Referências}

BOJUNGA, Cláudio. O artista do impossivel. Rio de Janeiro: Objetiva, 2001.p. 427.

CORBUSIER, Le. La ciudad del futuro. Versión castellana E. L. Revol. 2. ed. Buenos Aires: Ediciones Infinito, 1971.

KUBITSCHEK, Juscelino. Por que construí Brasilia. Rio de Janeiro: Bloch Editores, 1975.

. Meu caminho para Brasília. 50 anos em 5.

Rio de Janeiro: Bloch Editores, 1978, v. 3.

LEDRUT, Raymomd. Société réelle et societé imaginaire. Cahiers Internationaux de Sociologie, Paris, CIS, n $^{\circ} 82,1987$.

MAFFESOLI, Michel. La tribalización del monde. Paris : Grasset, 1992.

MOREIRA, Vânia Maria Losada, Brasilia: a construção da nacionalidade, um meio para muitos fins. Vitória: Edufes, 1998.

NIEMEYER, Oscar. Minha arquitetura. Rio de Janeiro: Revan, 2000. p. 35.

. Declaración en documentário Conterrâneos

velhos de guerra. Dirección de CARVALHO, Wladimir. Brasília: Producción- Vetr Visão Produções - CPCE-UnB, 1991.

Declaración a la Revista Módulo, n. 11, dezembro, Rio de Janeiro, ano 4, 1958.

PELAYO, Manuel Garcia. Mitos y símbolos políticos. Madrid: Taurus, 1964. 
SILVA, Ernesto. História de Brasília: um sonho, uma esperança, uma realidade. Brasília: Editora de Brasília, 1963.
VASCONCELOS, Adirson. A mudança da capital. 2. ed. Brasília: Gráfica e Editora Independência, 1978. 